\title{
Stage IVA Primary Peritoneal Cancer AJCC v8
}

National Cancer Institute

\section{Source}

National Cancer Institute. Stage IVA Primary Peritoneal Cancer A/CC v8. NCI Thesaurus.

Code C140013.

Stage IVA includes: Any T, Any N, M1a. M1a: Primary peritoneal cancer with pleural effusion with positive cytology. (from AJCC 8th Ed.) 